\title{
Dependence of the Surface Ozone Concentration in the Harima District on the Insolation and the Wind
}

\author{
By Hiroshi Yoshikado and Tateki Mizuno \\ National Research Institute for Pollution and Resources, \\ Onogawa, Yatabe-machi, Ibaraki 305, Japan \\ (Manuscript received 15 August 1984, in revised form 24 October 1985)
}

\begin{abstract}
Surface ozone concentrations measured for nine months in the Harima district were analysed to find a relationship with some meteorological factors. Emphasis is put on the high concentrations of ozone in the afternoon in late spring to summer.

In general, the daily maximum ozone concentration is proportional to the integrated insolation. The day-to-day fluctuation in the daily ozone maxima is mostly caused by the various patterns of the winds. Dependence of the particularly high ozone values on the location of the sites can be explained by the effect of advection due to land and sea breezes.
\end{abstract}

\section{Introduction}

Since early 1970s the photochemical air pollution has been a serious problem in Japan, and a large number of investigations have been devoted to reveal its behavior and mechanism. A fundamental relation between the photochemical air pollution and weather has been known: large insolution and relatively weak wind enhance the concentrations of photochemical pollutants. Based on a fundamental knowledge like this, high level pollutions can be predicted with an accuracy for practical use. However, in order to make strategies to control the photochemical air polution, it is necessary to trace it carefully from its sources to the area damaged by it and to clarify its mechanism together with the meteorological conditions which vary from day to day.

Recently some observational studies (e.g., Kikuchi, 1980; Tsuruta, 1983) revealed the behaviors of photochemical air pollution in the Kanto plain. They described the transport of pollutants by the land and sea breeze circulations. Mizuno and Yoshikado (1983) investigated the characteristics of the photochemical pollution in the Harima district during December 1979-August 1980. This area faces the Seto Inland Sea and has a quite different topography from the Kanto district: a relatively narrow plain and a nearly straight coastline. In the present study, the same data from the Harima district are analysed with emphasis on the relationship between the high ozone concentrations in the afternoon in late spring to summer and meteorological factors, such as insolation and land and sea breezes, which was not presented much in the previous work.

\section{Data}

On the coastal region of the Harima district, industrial complexes are distributed, and automobile traffic through the National Highway No. 2, the Chugoku Expressway, etc. is heavy. Therefore, the emission of various air pollutants is large there. In addition, the Hanshin district with a greater population and industries neighbors on the east of this area.

Concerning the observation and the data, Mizuno and Yoshikado (1983) can be referred to. Only a brief description of the observation sites is made here. The measurement of 
ozone concentration was made at three sites: Shirahama, Yamazaki and Iejima. Shirahama is about $1 \mathrm{~km}$ away from the shore and close to the industrial area. Yamazaki is located at the outskirts of a town in the Ibo valley, $27 \mathrm{~km}$ north of the river mouth. The height of the hills around the town is about $400 \mathrm{~m}$ above the basin bottom. Iejima island is about $10 \mathrm{~km}$ off the Harima coast, and the site is located on the north shore of the island.

Insolation was measured at Hirohata, a shore site $8 \mathrm{~km}$ west of Shirahama.

Wind speed and direction were also measured at the four sites mentioned above. However, the wind at Shirahama is affected by surrounding topography, so that the data from the air quality monitoring station at Shikama, $5 \mathrm{~km}$ west by northwest of Shirahama, were adopted as a representative of the coastal wind. The data were sampled every one hour as a 10 minute average with a resolution of $0.1 \mathrm{~ms}^{-1}$ and $2 \pi / 16 \mathrm{rad}(\mathrm{N}$, $\mathrm{NNE}$, etc.) for the wind speed larger than $0.4 \mathrm{~ms}^{-1}$.

\section{Analysis}

\subsection{General characteristics of ozone concentration}

(1) Relation with the insolation

Though the general relationship of ozone concentration with insolation and wind speed is already known, we begin with examining it in the studied area as a basis of analysis. Fig. 1 shows that the number of days with $C_{M} \geqq 80 \mathrm{ppb}$ increases abruptly up to about 10 days in May. This fact may indicate that in May the insolation as a dominant factor in ozone production becomes large enough to give daily maximum concentrations as high as 80 $\mathrm{ppb}$. In this paper, we are concerned with the days with large $C_{M}$ values $(\geqq 80 \mathrm{ppb}$ ) in the later four months and investigate the conditions under which they occurred.

As a representative of the insolution for each day, we adopt $Q_{15}$, an integrated value from sunrise to 1500 JST. As shown in Fig. 2 , a rough positive correlation is found between $Q_{15}$ and $C_{S M}$. The correlation coefficient is 0.671 , and

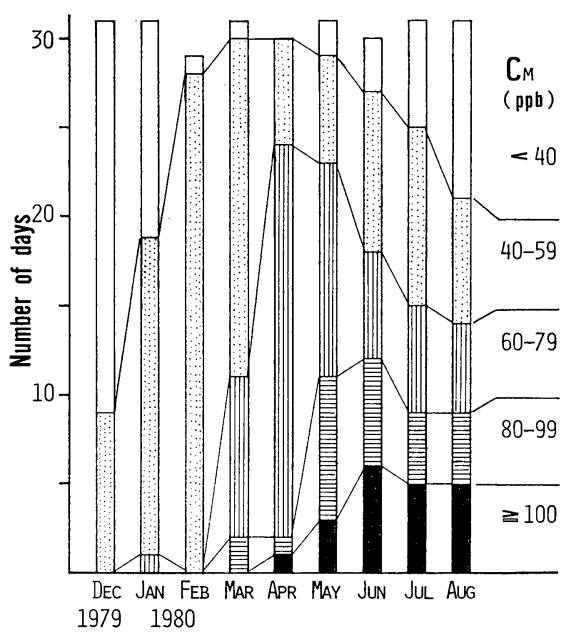

Fig. 1 Occurrence histogram of $C_{M}$, the largest of the daily maximum of the ozone concentration at the three sites.

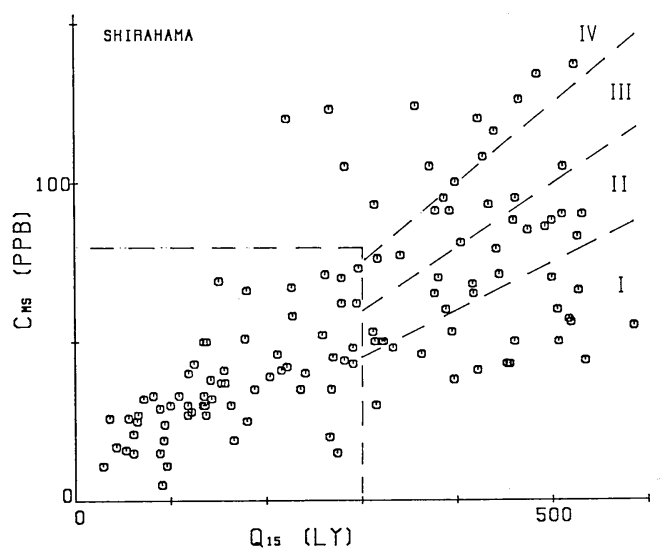

Fig. 2 Scatter diagram of $C_{S M}$, the daily maximum of ozone at Shirahama, vs $Q_{15}$, the insolation integrated from sunrise to $1500 \mathrm{JST}$. The dashed lines of demarcation are referred to Table 1 .

$$
C_{S M} / Q_{15}=0.23 \pm 0.11 \mathrm{ppb} / \mathrm{ly} \text {. }
$$

The daily maxima of the ozone concentrations at Yamazaki and Iejima, denoted by $C_{Y M}$ and $C_{I M}$ respectively, have relations with $Q_{15}$ similar to that in Fig. 2. In the following sections, assuming that the ozone consentration observed at each site is represented by its maximum for the day, and considering the insolation as the most basic factor dominating the ozone concentration, we try to relate the wind patterns with the day-to-day fluctuations of $C_{S M} / Q_{15}$, etc.. 
(2) Relation with the sea breeze

Yoshikado (1981) introduced a rough criterion to select the days of a typical sea breeze on the Harima coast. The outline of the criterion is as follows: (i) the surface wind at some sites near the shore are northerly or nearly calm at $0600 \mathrm{JST}$, (ii) they are southerly and larger than $1.5 \mathrm{~ms}^{-1}$ at 1200 or $1500 \mathrm{JST}$, and (iii) skies are not rainy in the daytime. According to this criterion, 49 days during the period from May to August were the "sea breeze days". $C_{M}$ exceeds $80 \mathrm{ppb}$ on 36 days out of them. Number of non- sea breeze days with $C_{M} \geqq 80 \mathrm{ppb}$ was only five. This fact suggests that the weather condition under which the sea breeze system forms is suitable for the rise in ozone concentration.

(3) Correlations between the sites

$C_{S M}, C_{Y M}$ and $C_{I M}$ have correlation coefficients as follows :

$$
\begin{aligned}
& C_{S M} \text { vs } C_{I M}: 0.92 \\
& C_{S M} \text { vs } C_{Y M}: 0.74 \\
& C_{I M} \text { vs } C_{Y M}: 0.74
\end{aligned}
$$

The least square method gives following relations :

$$
\begin{aligned}
& C_{I M}=0.89 C_{S_{M}}+0.2(\mathrm{ppb}) \\
& C_{S M}=0.80 C_{Y M}+7.0(\mathrm{ppb})
\end{aligned}
$$

As shown in Fig. 3, the distributions of the time of day at which the ozone concentration attains the maximum at Shirahama and Iejima are similar to each other with a time lag of 0-2 hours. However, that for Yamazaki is quite different from the others. The first peak around 1300 JST means the ozone concentration stopped increasing after that time

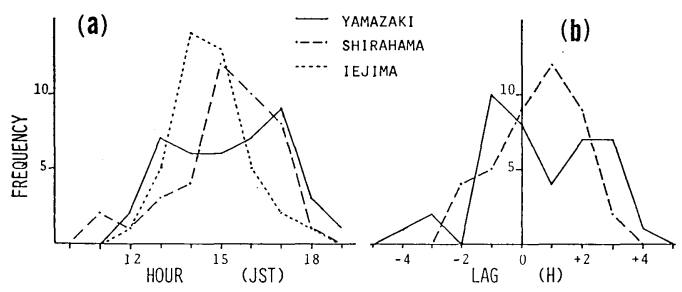

Fig. 3 Occurrence histogram of (a) the hours at which the daily maxima of ozone are attained, and (b) the time lags of the maxima at Shirahama and Yamazaki relative to those at Iejima, for the days with $C_{M} \geqq 80 \mathrm{ppb}$.

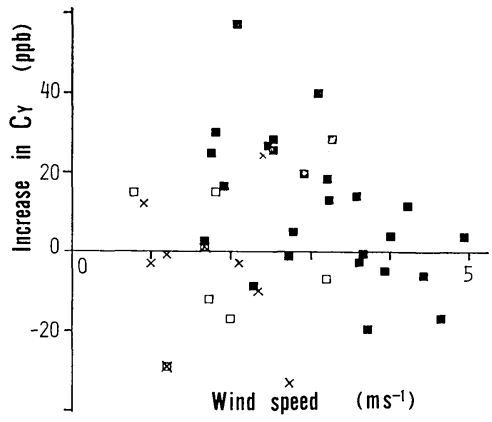

Fig. 4 Scatter diagram of the average wind speed $v s$. the increase in ozone at Yamazaki during 1300-1500 JST, for the days with $C_{M} \geqq$ $80 \mathrm{ppb}$. The integrated insolation during the three hours : $\geqq 150$ ly $(\boldsymbol{\square}, \times),<150$ ly $(\square)$; $\times$ represents the case that northerly winds were observed.

for some reasons. Fig. 4 implies that most cases of the time of $C_{Y M}$ earlier than 1500 JST are connected with the situations as follows.

i) The insolation decreased: $\leqq 150$ ly $(6.3$ $\mathrm{MJm}^{-2}$ ) for three hours between 1200 and 1500 JST. This condition is reflected on $Q_{15}$ and has been taken into consideration in Figs. 1 and 2.

ii) The wind speed increased at Yamazaki : $\geqq 3.5 \mathrm{~ms}^{-1}$ on the average over three observations between 1300 and 1500 JST. It is wellknown that a large wind speed generally reduces the pollution level. However, as is mentioned below, the ozone remains at a small value at Yamazaki also when the sea breeze is too weak to reach there.

iii) The southerly wind was interrupted at Yamazaki. This condition is considered further in the following sections.

As a result, the relation between $C_{I M}$ and $C_{S M}$ when they have large values may be fundamentally explained by the effect of onshore advection due to the sea breeze. Therefore, we examine below only $C_{S M}$ and $C_{Y M}$ in relation with the diurnal wind patterns.

\subsection{Dependence of the daily maximum ozone on the diurnal wind variation}

Table 1 summarizes the numbers of days with different values of $C_{S M} / Q_{15}$ and $C_{Y M} / Q_{15}$. In this table, the days with $Q_{15}<300$ ly and, at the same time, $C_{S M}$ (or $\left.C_{Y M}\right)<80 \mathrm{ppb}$ are 
Table 1 Numbers of days when $C_{S M} / Q_{15}$ and $C_{Y M} / Q_{15}$ fall within the given ranges (unit: $\mathrm{ppb} \mathrm{ly}^{-1}$ )

\begin{tabular}{|c|c|c|c|c|}
\hline Case & I & II & III & IV \\
\hline Range & $<.15$ & $.15-.20$ & $.20-.25$ & $\geqq 0.25$ \\
\hline$C_{S M} / Q_{15}$ & $18(8)$ & $18(13)$ & $9(8)$ & $13(11)$ \\
\hline$C_{Y M} / Q_{15}$ & $18(5)$ & $18(16)$ & 11 (11) & $11(8)$ \\
\hline
\end{tabular}

Note 1) The days with $Q_{15}<300 \mathrm{ly}$ and $C_{S M}$ (or $\left.C_{Y M}\right)<80 \mathrm{ppb}$ are excluded.

2) The numbers of days with the sea breeze after Yoshikado's (1981) criterion are shown in the parentheses.

omitted, since we are interested only in the days with large $C_{M}$ values and, for comparison, the days with small $C_{M}$ values in spite of strong insolation. The ranges for $C_{S M} / Q_{15}$ and $C_{Y M} / Q_{15}$ were selected arbitrarily. According to the criterion cited in $3.1(2)$ to separate sea breeze days from non- sea breeze days, most of the sample days in Case II-IV belong to the sea breeze days. Here, we focus on the difference in wind pattern between Cases I and IV. The wind hodographs for Case IV shown in Fig. 5(a)-(c) can be considered to represent "typical" patterns of land and sea breezes suitable for the rise in ozone concentration at each site. Though the wind hodographs for Case III are not so different from those for Case IV, the winds deviate farther and more times from the average for Case IV as the ranges of $C_{S_{M}} / Q_{15}$ and $C_{Y M} /$ $Q_{15}$ become smaller, as is summarized in Table 2 and some examples of the deviations are shown in Fig. 6. In particular, in Case I for $C_{Y M}$ the wind direction at Yamazaki has a northerly component all day long (Fig. 5(c)), which means that the sea breeze does not reach there. We may conclude, therefore, that deviations of winds from the averages for Case IV result in relative reductions in ozone concentration.

However, some exceptions do exist. On one sample day (9 August) in Case IV for both $C_{S M}$ and $C_{Y M}, \boldsymbol{v}_{S}$ falls within the respective standard deviation ranges for only three hours before 1500 JST. On the other hand, $\boldsymbol{v}_{S}$ in one sample (4 Junly) in Case I for both $C_{S M}$ and $C_{Y M}$ agrees with respective average pattern of Case IV for as much as six hours.

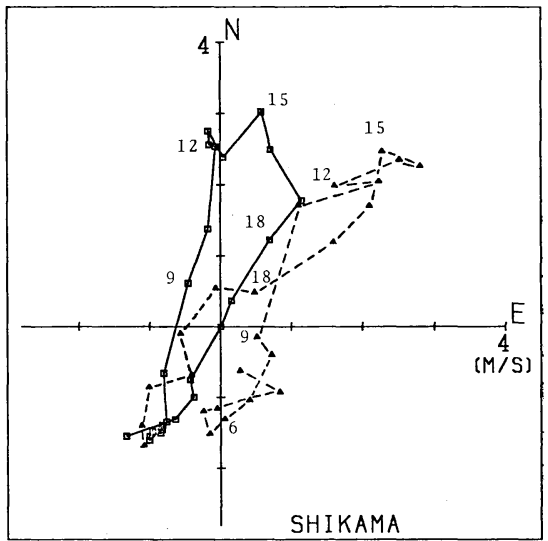

Fig. 5(a) Average wind hodographs at Shikama for Cases IV (solid line) and I (dashed line) for $C_{S M}$. The figures along the hodographs are hours (JST).

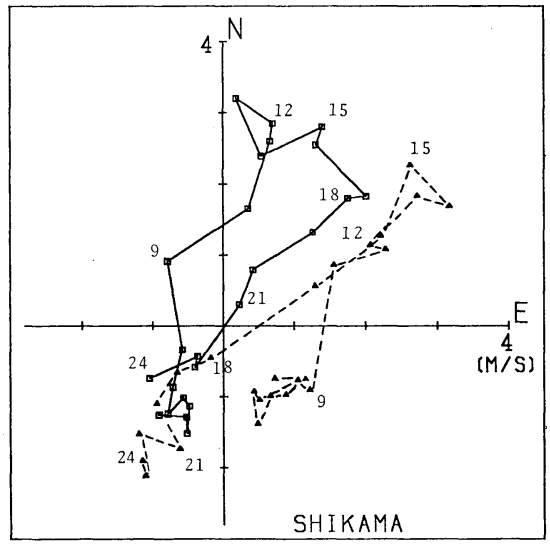

Fig. 5(b) Same as Fig. 5(a) except for $C_{Y M}$.

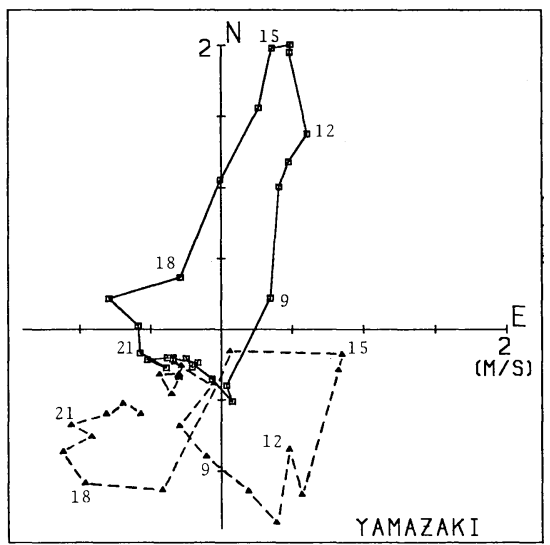

Fig. 5(c) Same as Fig. 5(a) except at Yamazaki for the cases for $C_{Y M}$. 
Table 2 Average hours during which the wind falls within the ranges of the standard deviations for Case IV during 01001500 JST

\begin{tabular}{cccc} 
Wind & \multicolumn{2}{c}{ at Shikama } & at Yamazaki \\
\cline { 1 - 1 } Case & for $C_{S M}$ & for $C_{Y M}$ & for $C_{Y M}$ \\
\cline { 2 - 3 } I & 3.2 & 2.6 & 3.0 \\
II & 5.0 & 5.0 & 3.7 \\
III & 7.4 & 5.2 & 5.9 \\
IV & 6.8 & 8.2 & 7.9 \\
\hline
\end{tabular}
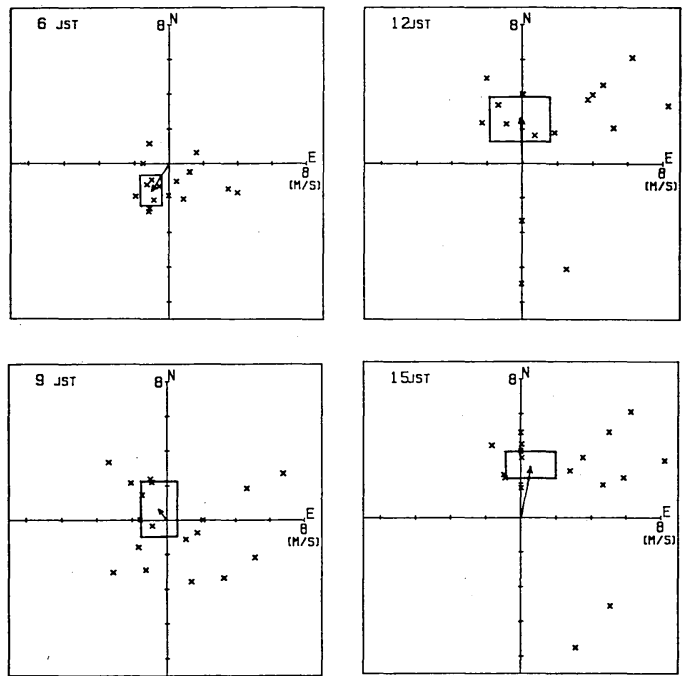

Fig. 6 Average of $v_{S}$, the wind at Shikama (arrows), with the standard deviations (rectangles) for Case IV, and individual vector heads of $\boldsymbol{v}_{S}$ (crosses) for the days in Case I, for $C_{S M}$ at every three hours.

A case study of these exceptional episodes may be interesting, but is beyond the scope of the present study.

\subsection{Dependence of the daily maximum ozone on the location}

The wind patterns of Case IV shown in Figs. 5(a) and (b) seem not to be essentially different. However, when the slight differences in these wind patterns are accumlated for more than ten hours, the resultant difference can beconne unexpectedly large. For the purpose of clarifying it, we use trajectories of air parcels which pass the sites at 1530 JST. In this study, one which passes the shore site is defined by

$$
-1 \text { hour } \times\left(v_{15}+v_{14}+v_{13}+\cdots\right)
$$

where $\boldsymbol{v}_{i}$ is the wind observed at hour $i$ (JST) at Shikama. The trajectory given by (1) is only an alternative expression to the wind hodograph, and may differ considerably from the actual trajectory to be calculated from estimated winds at successive points. They agree with each other only in a uniform wind field. Thinking of the general feature that an inland sea forms a convergence/. divergence zone in a land/ sea breeze system, we should presumably consider the extent of the trajectory given by (1) over the sea as is overestimated. Nevertheless, we expect some information on the relation between winds and ozone concetrations to be obtained from the trajectory given by (1), since no appropriate data concerning the winds above the sea is available.

Figs. 7(a) and (b), obtained in this way, show fairly different features. In Case IV for $C_{S M}$, many trajectories are traced back to the middle of the inland sea in the morning, and to the land east of the site, most coastal regions of which are urban and industrial areas, in the previous night. On the other hand, in Case IV for $C_{Y M}$, though five samples are included in common with the former case, most

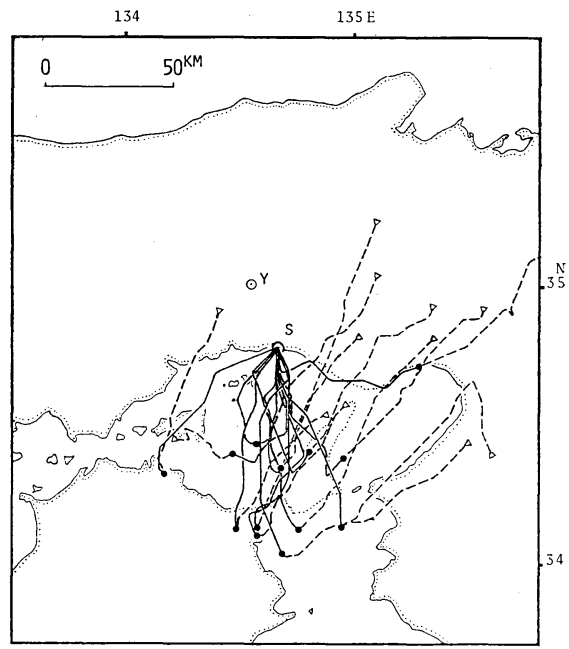

Fig. 7(a) Trajectories of the air parcel passing Shikema (S) at 1530 JST for the days in Case IV for $C_{S M}$. Closed circles indicate the positions at $0830 \mathrm{JST}$, and triangles at 2030 on the previous days. 


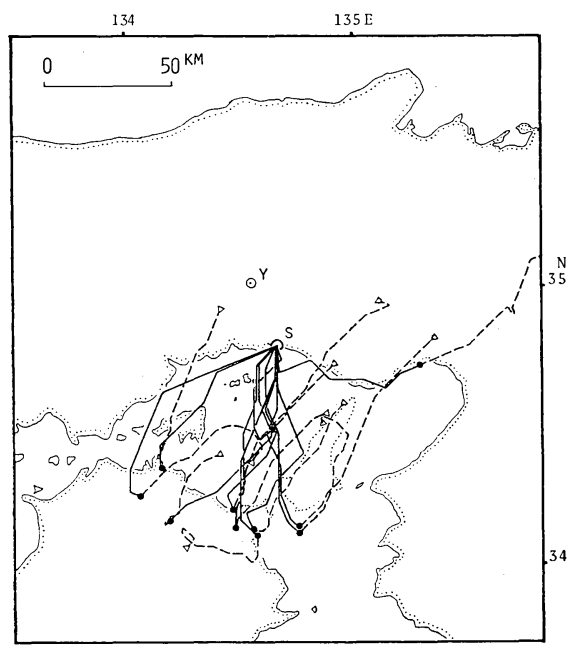

Fig. 7(b) Same as Fig. 7(a) except for $C_{Y M}$.

trajectories which originate from the east land and turn at the middle of the sea are excluded in this case. If we exclude such sample days on which both $C_{S_{M}} / Q_{15}$ and $C_{Y M} / Q_{05}$ have large values, and select days when $C_{S M}$ is much (by $30 \mathrm{ppb}$ or more) larger, or smaller, than $C_{Y M}$, difference between the two groups is more obvious. The characteristics of the trajectories for the group with $C_{S_{M}} \gg C_{Y M}$ are similar to those shown in Fig. $7(\mathrm{a})$, since six samples out of eight are included in this figure. On the other hand, the group with $C_{S M} \ll C_{Y M}$, though three samples of it are included also in Fig. 7(b), is less influenced by the major urban areas than the group in Fig. 7(b), and of course than that in Fig. 7(a).

Therefore, even if we take the deficiency of the definition (1) into consideration, we may infer that (i) the particularly high concentrations of ozone, or its precursors, originating from the urban and industrial areas in the studied region or on its east, are transported offshore by the land breeze, return back in the sea breeze system, and observed at the shore site, (ii) on some of the days which satisfy (i), the high concentration of ozone reaches the inland site, and (iii) when the air which reaches the shore in the afternoon does not originate from the major land on the previous day, the concentration of ozone is not enhanced so high at the shore site. Even in this case, the ozone can increase at the inland site.

Then, we examine the other case of (ii), namely, the days when the concentration of ozone at Yamazaki is not so high though that at Shirahama is very high, and the case of (iii) further, by means of the trajectory passing Yamazaki. This trajectory is calculated by interpolation of the winds observed at some air quality monitoring stations located between the shore and Yamazaki. As is shown in Fig. 8(a), on the days with $C_{S_{M}} \gg C_{Y M}$, the trajectories are not traced back to the shore, and in addition, the sea breezes are interrupted on some occasions by winds from the opposite direction, though exceptions exist. Therefore, it is considered that the high concentrations observed at the shore were not brought to Yamazaki because the sea breeze was too unsteady or did not reach there. The fact that the ozone stopped increasing or decreased on some trajectories which return back to Yamazaki after passing northward due to the sea breeze may indicate some process of vertical exchange of the air. On the other hand, Fig. 8(b) shows that the trajectories except one pass the industrial area arong the shoreline and reach Yamazaki fairly directly. Since the concentration of ozone was not so high at the shore for this group, it is likely to have increased during the travel from the shore to Yamazaki, presumably due to the

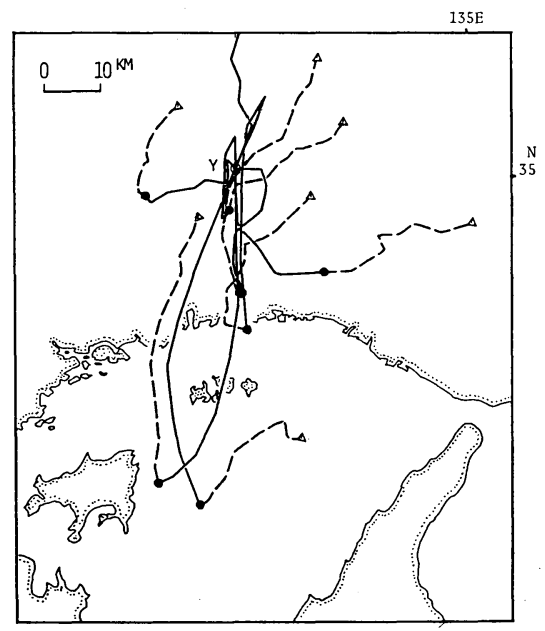

Fig. 8(a) Trajectories passing Yamazaki (Y) at $1530 \mathrm{JST}$ on the days with $C_{S M} \gg C_{Y M}$. Symbols have the same meanings as in Fig. 7(a). 


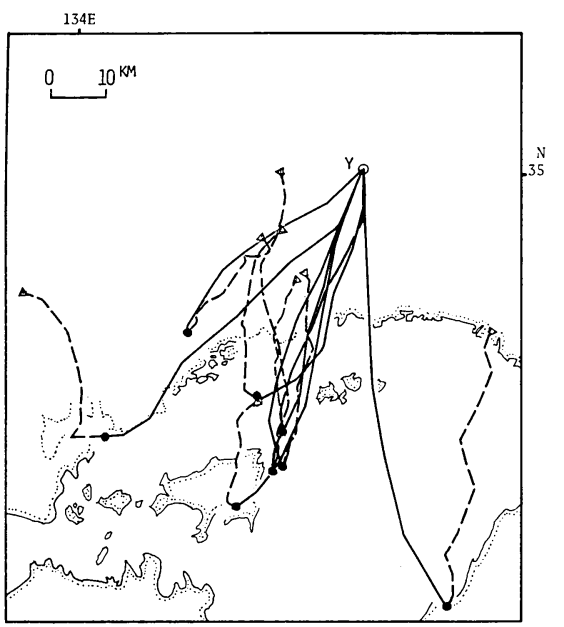

Fig. 8(b) Same as Fig. 8(a) except for the days with $C_{S M} \ll C_{Y M}$.

photochemical reactions of the pollutants supplied in the shore area. In such a case, if the sea breeze is too strong, the polluted air reach Yamazaki before the ozone producing reactions proceed sufficiently. This consideration agree with the condition ii) in 3.1(3).

\section{Conclusion}

We have investigated the behaviors of the daily maxima of ozone concentrations observed at an island, a shore and an inland site in the Harima district during May-August 1980. As a result, the following relations between the day-to-day variation of the daily maxima of ozone and meteorological factors are found.

As a general relation, there is a positive correlation between the maximum ozone and the insolation integrated from sunrise to 1500 JST, the average hour the maximum is attained.

The coefficient of correlation between the ozone maxima at the island site and the shore site has a high value of 0.92 . Usually the maximum ozone at the shore site is larger than that at the island site, and the time of occurrence of the maximum ozone at the shore site is $0-2$ hours later than that at the island site. These situations indicate the effect of onshore advection due to the sea breeze.

The relation between the shore site and the inland site is more complicated. Inspection of the wind patterns on individual days by means of the trajectories clearly shows the characteristic situation when the maximum ozone becomes large at each site. When the air parcel is traced back to the middle of the inland sea, and further back to the land east of the studied area, the maximum ozone is especially large at the shore site. On some of these days, the ozone concentration is enhanced at the inland site also. On most of the other days, the sea breeze is not predominant at the inland site.

On the other hand, in case that the maximum ozone at the inland site is much larger than that at the shore site, generally the sea breeze is stronger and the land breeze since the previous evening is weaker than the opposite case, and therefore the trajectory passing the shore site is not traced back to the land in the previous evening. In this case the large amount of ozone is likely to be produced during the travel from the shore to the inland site. However, the ozone at the inland site tends to stop increasing when the sea breeze is excessively strong in the afternoon. This may be partly because the pollutants reach the inland site before the ozone producing reactions proceed sufficiently.

In this study, the trajectories for the days with small ozone value are not presented for the brevity of the discussion. Here, we only mention about these days that the maximum ozone becomes smaller as the winds deviate farther from the "typical" patterns of diurnal variation on such days that the maximum ozone attains an especially high value.

As summarized above, the various situations that the high concentrations of ozone occur are connected with the day-to-day variations in pattern of the land and sea breezes. In addition, the sea breeze pattern is affected by the synoptic pressure distribution as Yoshikado (1981) investigated for the same area as in the present study. Consequently, it is inferred that the daily maximum of ozone varies in relation with the synoptic pattern, even if the insolation is the same. In fact, we have detected some tendency of that correlation in the present data, but not obtained a clear evidence probably because of the interference of other factors. 


\section{Acknowledgements}

The ozone measurement was carried out as part of the program for development of a photochemical air pollution control system sponsored by the Ministry of International Trade and Industry. The authors express their thanks to Mr. Keizo Kobayashi of the Industrial Pollution Control Association of Japan, and to the staffs of municipal government offices in the studied area, for arranging the data.

\section{References}

Kikuchi, R., 1980: A climatological study on the distribution of air pollution (in Japanese). Bull. Chiba Prefectural Res. Inst. for Environ. Pollution, 12, 13-129.

Mizuno, T. and H. Yoshikado, 1983: On some characteristics of the diurnal variation of $\mathrm{O}_{3}$ observed in island, urban and rural areas. Atmos. Environ., 17, 2575-2582.

Tsuruta, H., 1983: Study on the transport and modification processes of pollutants in the land and sea breeze in the southern Kanto district (in Japanese). Rep. of Yokohama Municipal Pollution Res. Insti., No. 47, 5-127.

Yoshikado, H., 1981: Statistical analyses of the sea breeze pattern in relation to general weather conditions. J. Meteor. Soc. Japan, 59, 98-107.

\title{
播磨地域のオゾン高濃度と日射・風速の関係
}

\author{
吉 門 洋 ・水 野 建 樹 \\ 公害資源研究所
}

瀬戸内海播磨灘に面した工業地域周辺と沖合の島, および内陸の計 3 地点で測定されたオゾン濃度データを, $5 \sim 8$ 月の日中の高濃度に注目して解析した。オゾン日最高濃度は概してその平均出現時刻15時までの積算日 射量に比例するが，ばらつきは大きい。そのばらつきのかなりの部分は風の日変化パターンと関連づけられる。 オン゙ン高濃度出現の測定地点間の関係は海陸風の移流効果に依存していることが示される。 